\title{
Pelagic larval duration of 10 temperate cryptobenthic fishes
}

\author{
R. Beldade, T. Pedro and E. J. Gonçalves* \\ Eco-Ethology Research Unit, Instituto Superior de Psicologia Aplicada, \\ R. Jardim do Tabaco 34, 1149-041 Lisboa, Portugal
}

(Received 1 June 2006, Accepted 17 February 2007)

\begin{abstract}
The pelagic larval duration $\left(D_{\mathrm{PL}}\right)$ for 10 temperate cryptobenthic species belonging to three families: Gobiidae, Gobiesocidae and Blenniidae was investigated. Overall, the Gobiesocidae presented short $D_{\mathrm{PL}} \mathrm{S}$ varying between 11 and 18 days, the Gobiidae's $D_{\mathrm{PL}}$ ranged between 14 and 39 days, and Parablennius pilicornis (Blenniidae) had an average of 33 days (range 31-37 days). Two subtypes of settlement marks were found among individuals of the same species.

(C) 2007 The Authors

Journal compilation (c) 2007 The Fisheries Society of the British Isles
\end{abstract}

Key words: cryptobenthic fishes; pelagic larval duration; settlement marks.

\section{INTRODUCTION}

Many marine organisms, including cryptobenthic fishes, have complex life cycles (Roughgarden et al., 1988) divided in two main phases: the larval stage, which is generally spent in the plankton as gametes and larvae, and the juvenile and adult phase, which starts when the larvae settle into benthic habitats. Between these phases there is a transition period (i.e. settlement), which is characterized by more or less abrupt morphological and physiological changes (Leis, 1991). Settlement from the plankton to the benthos may be marked by a rapid change in width of daily increments in fish otoliths (Wilson \& McCormick, 1997). These transition zones or settlement marks allow the duration of planktonic life and the timing of settlement to be estimated (Wellington \& Victor, 1989).

In coastal areas, cryptobenthic species can be very abundant (La Mesa et al., 2004) and their importance in coastal processes has only recently been assessed (Depczynski \& Bellwood, 2003). These fishes have very strong habitat associations as adults and juveniles (Patzner, 1999). The larval biology of cryptobenthic fishes is still largely unknown, but some biological characteristics suggest that some species may be able to remain nearshore. Larvae of these

*Author to whom correspondence should be addressed. Tel.: +35 1218811700 ; fax: +35 121 8860954; email: emanuel@ispa.pt 
fishes typically hatch from benthic eggs, present functional eyes, fins and guts, and have better swimming abilities than larvae of pelagic species (Thresher, 1984; Hickford \& Schiel, 2003). The presence of all larval stages close to shore has been described for some cryptobenthic fishes (Beldade et al., 2006).

Information on the planktonic larval durations of these fishes is important for studies of dispersal potential, connectivity between populations and conservation biology. This study aimed at contributing to fill existing gaps on basic knowledge of early life-history traits of small cryptobenthic reef fishes. The pelagic larval durations and settlement marks on otoliths of 10 temperate cryptobenthic fishes were investigated.

\section{MATERIALS AND METHODS}

Newly settled juvenile fishes were captured in shallow rocky substrata at two Portuguese marine protected areas: Arrábida Nature Park $\left(38^{\circ} 26^{\prime} \mathrm{N} ; 9^{\circ} 01^{\prime} \mathrm{W}\right)$ and Ria Formosa Nature Park $\left(36^{\circ} 59^{\prime} \mathrm{N} ; 7^{\circ} 52^{\prime} \mathrm{W}\right)$. All specimens were collected during the breeding seasons of these coastal species, between June and September. Collections were performed with a small hand-net and using the anaesthetic quinaldine dissolved in alcohol (1 quinaldine:15 alcohol). The specimens were killed with an overdose of quinaldine and stored in $70 \%$ ethanol prior to otolith extraction. Specimens were measured (total length, $L_{\mathrm{T}}$, in $\mathrm{mm}$ ) to the nearest $0.01 \mathrm{~mm}$ under a binocular microscope.

A total of 78 specimens belonging to 10 species (five Gobiidae, four Gobiesocidae and one Blenniidae) were examined. Lapilli and sagittae otoliths were extracted from each fish and processed following Secor et al. (1992). Otoliths were mounted in thermoplastic cement Crystal Bond ${ }^{\mathrm{TM}}$ (Aremco Products ${ }^{\circledR}$ Inc., Valley Cottage, NY, U.S.A.), and polished using 12 to $0 \cdot 3 \mu \mathrm{m}$ grit lapping film (3M products St Paul, MN, U.S.A.) to obtain a section through the nucleus. Otoliths were then viewed under immersion oil, using a compound microscope (Olympus BX50 light microscope) at $\times 1000$ magnification. The number of daily increments was determined from three replicate counts from two different observers, and the mean value was taken. Counts from different observers that did not deviate by more than three increments were accepted. Counts and measurements were performed in both otolith types, sagittae and lapilli, for all species except Gobius gasteveni Miller and Chromogobius britoi Van Tassell because the sagittae of these species were not legible. Since no differences were found between otolith types, the otolith that had increments of higher clarity was selected.

The otoliths' increment density and width were also recorded. Settlement marks (SM) were identified through density changes in the otoliths. ImagePro-Plus $4.5^{\circledR}$ software was used to confirm the density transitions, through the analysis of grey level profiles, and measure increment widths across the SM. Pelagic larval duration $\left(D_{\mathrm{PL}}\right)$ was backcalculated based on the increments occurring from the nucleus (beginning at the first well defined increment for each species) to the settlement mark. The daily nature of the increments for the species was assumed based on several previous reports on a range of other cryptobenthic fishes in both temperate and tropical regions (Sponaugle \& Cowen, 1994; Iglesias et al., 1997; Shafer, 2000). Given that the exact timing of initiation of increment deposition in the species studied is unknown, the counts may over- or underestimate the $D_{\mathrm{PL}}$ by a few days (Raventós \& Macpherson, 2001).

\section{RESULTS}

Two settlement mark types were identified. The most common settlement mark type was type Ia characterized by a sharp decrease in increment width across the settlement mark completed within a few increments (Wilson \& McCormick, 1999). In two gobies Gobius xanthocephalus Heymer \& Zander 
and Gobius paganellus L., a type Ib SM, which is a multi-increment transition (Wilson \& McCormick, 1999), was also found.

A summary of results on $D_{\mathrm{PL}} \mathrm{S}$ and SM types is presented in Table I for the three families. The gobies, G. xanthocephalus and G. paganellus had an average $D_{\mathrm{PL}}$ of 30 and 26 days respectively. Two different subtypes of settlement marks were observed in each of these species corresponding to a single transition increment [type Ia; Fig. 1(a)] or a few transition increments [type Ib; Figs 1(b) and 2(a)]. Increment widths, immediately before and after the SM, are given in Table I. The grey level profiles for each SM type are clearly different and reflect the number of transition increments [Figs 1(b) and 2(b)]. G. gasteveni and $C$. britoi, presented shorter $D_{\mathrm{PL}} \mathrm{S}$ averaging 20 and 19 days respectively. In the case of Pomatoschistus pictus (Malm), there was no clear settlement mark in the otoliths within the first 76 increments (maximum count). Neither a change in increment width nor a clear change in increment density was observed in any of the specimens analysed.

The Gobiesocidae presented shorter $D_{\mathrm{PL}} \mathrm{S}$ than the gobies, but $D_{\mathrm{PL}}$ values varied among these clingfishes. The average $D_{\mathrm{PL}}$ was 14 days for Apletodon dentatus (Facciolà), 15 days for Opeatogenys gracilis (Canestrini) and Lepadogaster lepadogaster (Bonnaterre), and 16 days for Lepadogaster candolii Risso. Newly settled individuals were collected for all these species, i.e. with very few increments following the settlement mark. All these clingfishes settle in sizes close or smaller than $1 \mathrm{~cm}$.

Finally, the Blenniidae, Parablennius pilicornis (Cuvier), presented the longest $D_{\mathrm{PL}}$ among all species studied here (averaging 33 days) and the otoliths displayed a type Ia settlement mark.

\section{DISCUSSION}

In this study, the $D_{\mathrm{PL}}$ are presented for a number of cryptobenthic species based on density and increment widths in otoliths. Type Ia settlement mark, i.e. a sharp decrease in increment width across the settlement mark, was identified in all species. This is the most common type found among bottom-dwelling species including all Blenniidae, Gobiidae and Gobiesocidae analysed by Raventós \& Macpherson (2001). Gobius xanthocephalus and G. paganellus presented two settlement mark subtypes Ia and Ib. Settlement mark types are known to vary among species, even within the same genus (Wilson \& McCormick, 1999), but, as far as is known, this is the first time that two subtypes of settlement marks are found within the same species.

Differences between increment widths before and after the SM were clear for all species, and in both otolith types. Since the sagittae present a faster growth, increment widths were wider than in the lapilli. Sagittae increment widths measured in this study are consistent with the widths described for other fish families (Wilson \& McCormick, 1999).

The Gobiidae studied here presented average $D_{\mathrm{PL}} \mathrm{s}$ ranging from 19 to 30 days. Gobius xanthocephalus presented the highest variation in $D_{\mathrm{PL}}$ ranges, from 24 to 39 days. This result is interesting since it is known that a possible mechanism to maximize chances of returning to coastal areas in reef fishes is extending the duration of the competence period (i.e. the period at the end of the 


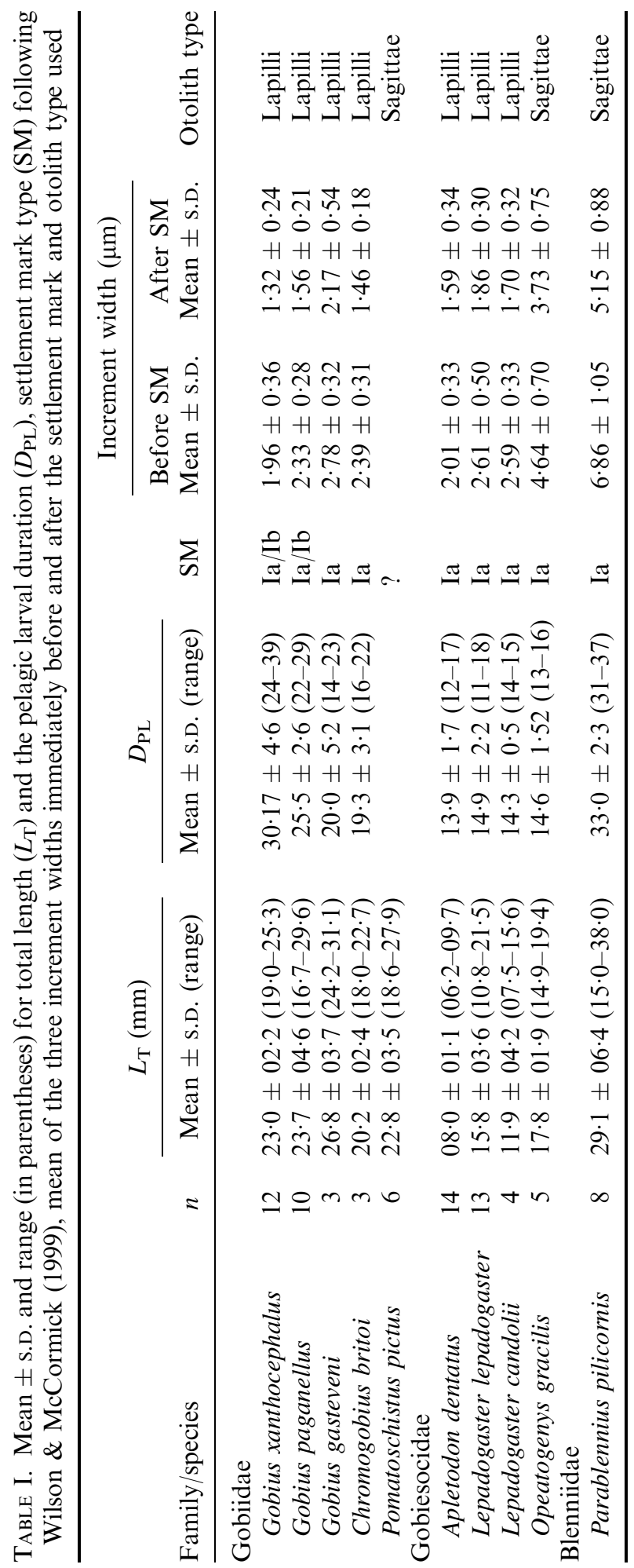


(a)

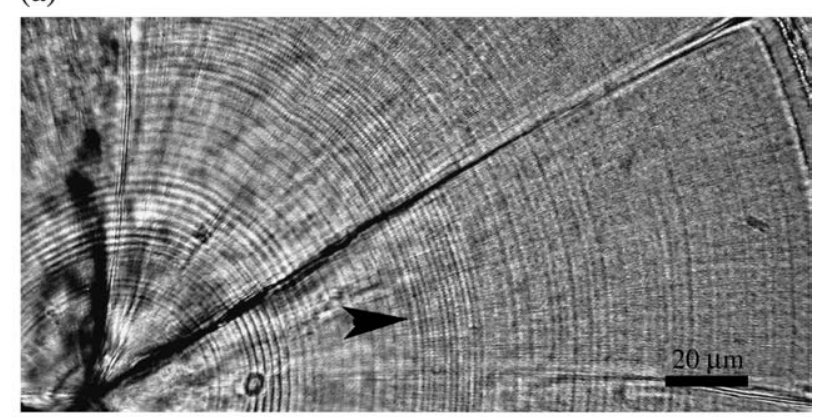

(b)

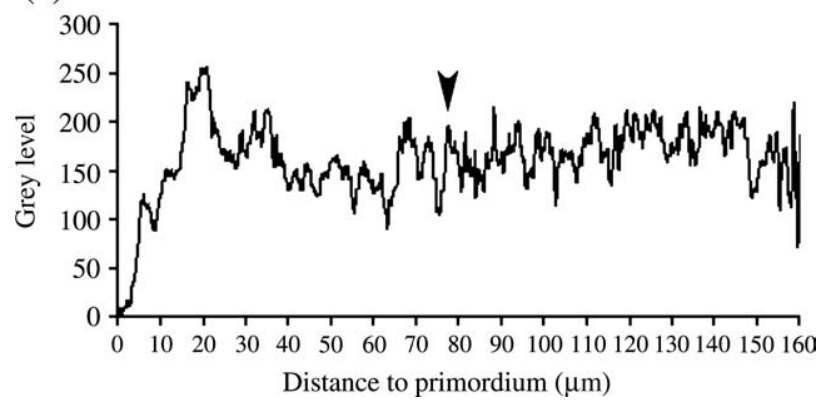

FIG. 1. (a) Gobius paganellus lapilli otolith $(\times 1000$ magnification $)$, displaying a type Ia settlement mark ( ) and (b) otolith density variation shown by grey level profiles.

larval stage during which larvae are able to settle) (Victor, 1986; McCormick, 1994). For P. pictus, no clear settlement mark was found. Newly settled individuals and juveniles of this species can be considered epibenthic since they occur both on the sandy substratum and also swim frequently in the water column, remaining close to the bottom (pers. obs.). As late stage larvae, they school close to the bottom in the vicinity of rocky reefs (Beldade et al., 2006). This means that they probably do not undergo an abrupt habitat change during settlement, which could explain the lack of a clear mark in the otoliths of this species. The relatively low number of specimens analysed, however, puts some caution on interpreting these results.

The Gobiesocidae analysed in this study presented short average $D_{\mathrm{PL}} \mathrm{s}(14-15$ days). This might suggest a small dispersion potential for these species. In fact, Macpherson \& Raventós (2006) have studied the $D_{\mathrm{PL}}$ in several temperate clingfish species and also found short $D_{\mathrm{PL}} \mathrm{S}$ in those species which span over relatively small geographic areas of distribution. The relationship between dispersion potential and the geographic segregation or connectivity in these species may in the future be corroborated through population genetic studies.

The only Blenniidae captured in this study, $P$. pilicornis, had the longest $D_{\mathrm{PL}}$ among the species analysed here (33 days). Macpherson \& Raventós (2006) found a slightly shorter $D_{\mathrm{PL}}$ for this species (28 days), but they only analysed two specimens. Interestingly, $P$. pilicornis larvae are known to disperse offshore 
(a)

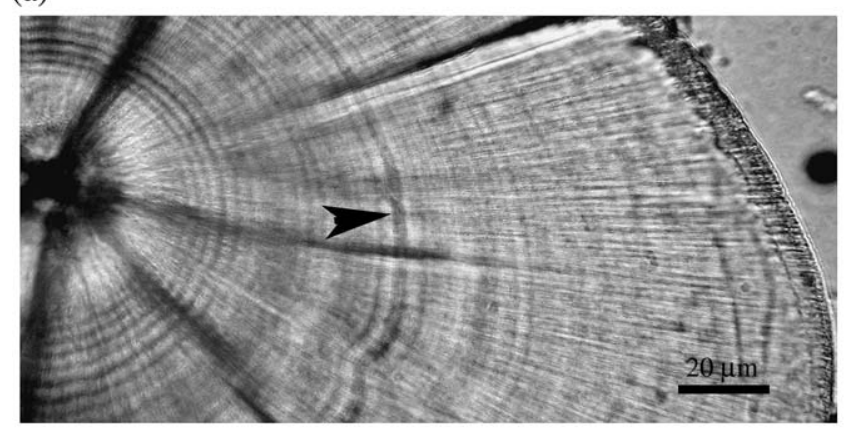

(b)

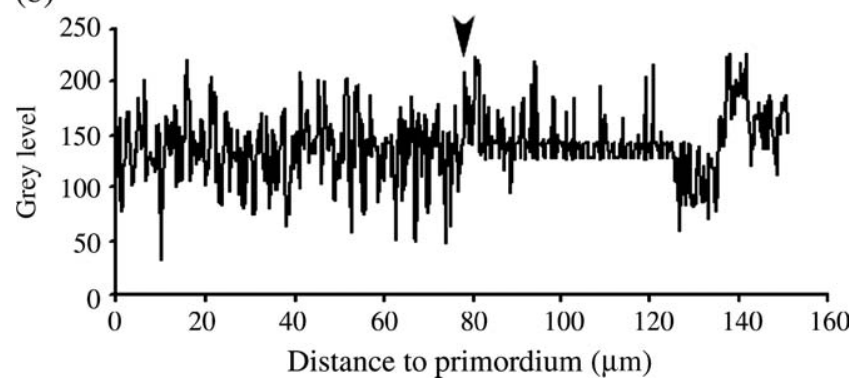

FIG. 2. (a) Gobius xanthocephalus lapilli otolith $(\times 1000$ magnification), displaying a type Ib settlement mark ( $\bullet$ ) and (b) otolith density variation shown by grey level profiles.

(Olivar, 1986; Borges et al., in press), which is consistent with the longest planktonic life.

This study adds to the knowledge on the early life history of small coastal marine fishes by describing the pelagic larval durations of 10 temperate cryptobenthic species. This type of studies may be integrated in the future with studies on population genetics and larval biology of these species, which may provide further insight into the larval biology of these poorly studied fishes.

We would like to thank N. Raventós for help in sorting some methodological problems, M. Barbosa for the Apletodon dentatus specimens, H. Folhas, G. Franco and the Arrábida Marine Park for logistic support. This study was supported by Fundação para a Ciência e a Tecnologia (FCT) through the Pluriannual Programme (UI\&D $331 / 94$ ) and the project POCTI/BSE/38350/2001. R.B. was supported by an FCT $\mathrm{PhD}$ grant (SFRH/BD/1013/2000).

\section{References}

Beldade, R., Borges, R. \& Gonçalves, E. J. (2006). Depth distribution of very nearshore temperate fish larval assemblages at close proximity to the rocky substrate. Journal of Plankton Research 28, 1003-1013. doi: 10.1093/plankt/fbl035

Borges, R., Beldade, R. \& Gonçalves, E. J. (2007). Vertical structure of very nearshore larval fish assemblages in a temperate rocky coast. Marine Biology 151, 1349-1363. doi: $10.1007 / \mathrm{s} 00227-006-0574-\mathrm{z}$ 
Depczynski, M. \& Bellwood, D. R. (2003). The role of cryptobenthic reef fishes in coral reef trophodynamics. Marine Ecology Progress Series 256, 183-191.

Hickford, M. J. H. \& Schiel, D. R. (2003). Comparative dispersal of larvae from demersal versus pelagic spawning fishes. Marine Ecology Progress Series 252, 255-271.

Iglesias, M., Brothers, E. B. \& Morales-Nin, B. (1997). Validation of daily increment deposition in otoliths. Age and growth determination of Aphia minuta (Pisces: Gobiidae) from the northwest Mediterranean. Marine Biology 129, 279-287. doi: $10.1007 / \mathrm{s} 002270050168$

La Mesa, G., Micalizzi, M., Giaccone, G. \& Vacchi, M. (2004). Cryptobenthic fishes of the "Ciclopi Islands" marine reserve (central Mediterranean Sea): assemblage composition, structure and relations with habitat features. Marine Biology 145, 233-242. doi: 10.1007/s00227-004-1315-9

Leis, J. M. (1991). The pelagic stage of reef fishes: the larval biology of coral reef fishes. In The Ecology of Fishes on Coral Reefs (Sale, P. F., ed.), pp. 183-230. San Diego, CA: Academic Press.

Macpherson, E. \& Raventós, N. (2006). Relationship between pelagic larval duration and geographic distribution of Mediterranean littoral fishes. Marine Ecology Progress Series 327, 257-265.

McCormick, M. I. (1994). Variability in age and size at settlement of the tropical goatfish Upeneus tragula (Mullidae) in the great barrier reef lagoon. Marine Ecology Progress Series 103, 1-15.

Olivar, M. P. (1986). Development and distribution of Parablennius pilicornis (Cuvier) larvae (Teleostei: Blenniidae) off Namibia. South African Journal of Marine Sciences 4, 193-201.

Patzner, R. A. (1999). Habitat utilization and depth distribution of small cryptobenthic fishes (Blenniidae, Gobiesocidae, Gobiidae, Tripterygiidae) in Ibiza (Western Mediterranean). Environmental Biology of Fishes 55, 207-214. doi: 10.1023/A: 1007535808710

Raventós, N. \& Macpherson, E. (2001). Planktonic larval duration and settlement marks on the otoliths of Mediterranean littoral fishes. Marine Biology 138, 1115-1120. doi: $10.1007 / \mathrm{s} 002270000535$

Roughgarden, J., Gains, S. \& Possingham, H. (1988). Recruitment dynamics in complex life cycles. Science 241, 1460-1466. doi: 10.1126/science.11538249

Secor, D. H., Dean, J. M. \& Laban, E. H. (1992). Otolith removal and preparation for microstructural examination. In Otolith Microstructure Examination and Analysis (Stevenson, D. K. \& Campana, S. E., eds), pp. 19-57. Canadian Special Publication of Fisheries and Aquatic Sciences 117.

Shafer, D. J. (2000). Evaluation of periodic and aperiodic otolith structure and somaticotolith scaling for use in retrospective life history analysis of a tropical marine goby, Bathygobius coalitus. Marine Ecology Progress Series 199, 217-229.

Sponaugle, S. \& Cowen, R. K. (1994). Larval durations and recruitment patterns of two Caribbean gobies (Gobiidae): contrasting early life histories in demersal spawners. Marine Biology 120, 133-143. doi: 10.1007/BF00381949

Thresher, R. E. (1984). Reproduction in Reef Fishes. Neptune City, NJ: T.F.H. Publications.

Victor, B. C. (1986). Delayed metamorphosis with reduced larval growth in a coral reef fish (Thalassoma bifasciatum). Canadian Journal of Fisheries and Aquatic Sciences 43, 1208-1213.

Wellington, G. M. \& Victor, B. C. (1989). Planktonic larval duration of one hundred species of Pacific and Atlantic damselfishes (Pomacentridae). Marine Biology 101, 557-567. doi: 10.1007/BF00541659

Wilson, D. T. \& McCormick, M. I. (1997). Spatial and temporal validation of settlementmarks in the otoliths of tropical reef fishes. Marine Ecology Progress Series 153, 259-271.

Wilson, D. T. \& McCormick, M. I. (1999). Microstructure of settlement-marks in the otoliths of tropical reef fishes. Marine Biology 134, 29-41. doi: 10.1007/ s002270050522 